\title{
Chronic lung disease and a history of tuberculosis (post-tuberculosis lung disease): Clinical features and in-hospital outcomes in a resource-limited setting with a high HIV burden
}

\author{
P Mkoko, ${ }^{1} \mathrm{MB}$ ChB, FCP; S Naidoo, ${ }^{2} \mathrm{MB}$ ChB; L C Mbanga, ${ }^{3} \mathrm{MB}$ ChB; F Nomvete, ${ }^{2} \mathrm{MB}$ ChB, FCP, Cert Gastroenterology (SA); \\ R Muloiwa, ${ }^{4} \mathrm{MB}$ ChB, FCP Cert ID (SA); $\mathbf{S}$ Dlamini, ${ }^{5} \mathrm{MB}$ ChB, FCP, Cert ID (SA) \begin{abstract}
Cape Town, South Africa
${ }^{2}$ Department of Medicine, Dora Nginza Hospital, Nelson Mandela Bay, South Africa

${ }^{3}$ Department of Medicine, Faculty of Health Sciences, University of Cape Town and Groote Schuur Hospital, Cape Town, South Africa

${ }^{4}$ Department of Paediatrics and Child Health, Faculty of Health Sciences, University of Cape Town and Groote Schuur Hospital, Cape Town, South Africa

${ }^{5}$ Division of Infectious Diseases, Department of Medicine, Faculty of Health Sciences, University of Cape Town and Groote Schuur Hospital, Cape Town, South Africa
\end{abstract} \\ ${ }^{1}$ Division of Cardiology, Department of Medicine, Faculty of Health Sciences, University of Cape Town and Groote Schuur Hospital,
}

Corresponding author: P Mkoko (mkoko25@me.com)

\begin{abstract}
Background. Many patients with previous pulmonary tuberculosis (PTB) continue to experience respiratory symptoms long after completion of tuberculosis (TB) therapy, often resulting in numerous hospital visits and admissions.

Objectives. To describe the profile of patients with chronic lung disease (CLD) with or without a history of PTB, and their in-hospital outcomes. Methods. We conducted a retrospective review of patients with CLD admitted with respiratory symptoms to Dora Nginza Hospital, Port Elizabeth, South Africa, from 1 April 2016 to 31 October 2016. These patients were divided into two groups: CLD with a history of PTB (CLD-TB) and CLD without a history of PTB. Patients with current culture-positive TB were excluded. Baseline characteristics and clinical outcomes (duration of hospitalisation and in-hospital mortality) were compared between the two groups.

Results. During the study period, a total of 4884 patients were admitted and 242 patients received a diagnosis of CLD. In the CLD patient group, 173 had CLD-TB and 69 had no history of PTB. Patients with CLD-TB presented with respiratory symptoms a median of 41 months (interquartile range (IQR) 101) after completion of TB therapy. CLD-TB patients were predominantly male (59.5\%), and compared with patients with no history of PTB were more likely to be HIV-positive ( $49.7 \%$ v. $8.7 \% ; p=0.001)$ and had had more frequent hospital admissions before the current admission (median 2.0 (IQR 2.0) v. $0 ; p=0.001$ ) and longer hospital stays (median 5 days (IQR 7) v. 2 (4); $p=0.002$ ). However, there was no statistically significant difference in in-hospital mortality between the two groups ( $17.3 \%$ v. $10.1 \% ; p=0.165)$. Conclusions. In patients with CLD, a history of PTB is associated with numerous hospital admissions and longer hospital stays but not with increased in-hospital mortality. TB therefore continues to be a public health burden long after cure of active disease.
\end{abstract}

S Afr Med J 2019;109(3):169-173. DOI:10.7196/SAMJ.2019.v109i3.13366

Tuberculosis (TB) has afflicted mankind for millennia and continues to be a major public health burden. In 2015, an estimated 10.4 million people contracted TB and up 1.8 million people succumbed to the disease. ${ }^{[1]}$ The vast majority of TB cases occur in low- and middleincome countries, particularly those where there is an intersection of the TB epidemic and the HIV epidemic. ${ }^{[2]}$ There have recently been major advances in the diagnostics and treatment of TB. ${ }^{[3,4]}$ Consequently, the mortality associated with TB dropped by at least $47 \%$ from 1990 to 2015 . ${ }^{[1]}$

The lungs are the most common site of TB infection, and up to $81 \%$ of reported TB cases are pulmonary TB (PTB). ${ }^{[5]}$ TB cure is defined as the sterility of body sites or specimens previously infected by Mycobacterium tuberculosis or completion of a predetermined dose and duration of TB therapy ${ }^{[6,7]}$ However, a substantial proportion of patients $\left(40-97 \%^{[8-13]}\right)$ continue to experience respiratory symptoms long after completion of therapy. In addition, $40-100 \%$ of patients with previous PTB are reported to have persistent chest radiographic abnormalities. ${ }^{[8,13,14]}$ Older age, female sex, longer duration of symptoms prior to the commencement of therapy, poor compliance with therapy and a history of previous PTB are factors associated with poor radiographic resolution after completion of therapy. ${ }^{[15]}$

\section{Objectives}

The clinical implications of residual respiratory symptoms in post-TB patients in resource-constrained settings are unknown. Moreover, there are no guideline recommendations on the management of post-TB lung disease. The objective of this study was to describe the clinical profile and in-hospital outcomes of patients with chronic lung disease (CLD) and a documented history of previous PTB (CLDTB) compared with patients with CLD and no history of PTB, in a resource-constrained setting.

\section{Methods}

\section{Study design}

This study was a retrospective review of patients admitted to the Department of Medicine at Dora Nginza Hospital from 1 April 2016 
to 31 October 2016. Dora Nginza Hospital is a district hospital in Zwide township in the Nelson Mandela Bay Municipality (Port Elizabeth), South Africa. In 2011 Nelson Mandela Bay had a population of 1152115 and an up to $36.6 \%$ unemployment rate. ${ }^{[16]}$ The Department of Medicine at the hospital is a 120-bed unit with no intensive care or high-care unit and limited access to radiological imaging other than plain chest radiography.

\section{Study population}

Clinical notes, discharge summaries and the death notification registry were reviewed to identify patients who received a primary or secondary diagnosis of CLD. The patients identified were then divided into two groups: (i) CLD-TB; and (ii) CLD with no documented history of previous PTB. All patients with a current diagnosis of culturepositive TB were excluded $(n=905)$. The study was approved by the Walter Sisulu University Human Research Committee (ref. no. 005/2017). Informed consent was waived because this was a retrospective study.

\section{Data collection}

A standardised data collection form that included patient demographic details, comorbidities, history of previous PTB, time in months since completion of antiTB therapy for the last episode of PTB, and details of the index admission was used. Blood results and sputum microbiology results were retrieved from the National Health Laboratory Service database. Sputum culture micro-organisms are only reported for specimens with $>25$ neutrophils and $\leq 10$ epithelial cells per $100 \times$ magnification on Gram stain microscopy. ${ }^{[17]}$ Admission chest radiographs from the Dora Nginza Hospital Picture Archiving and Communications System were reviewed and graded for the extent of radiographic abnormalities as described by Willcox and
Ferguson. ${ }^{[18]}$ Briefly, each lung was divided into three zones, upper, middle and lower, by horizontal lines dividing the vertical distance from the pulmonary apex to the hemidiaphragm into three equal parts. with one zone involved without cavitation, grade 2 disease was involvement of two or three zones or one zone with cavitation, and grade 3 disease was severe involvement with more than three zones involved with or without cavitation. ${ }^{[18]}$ The chest radiographs and electrocardiograms (ECGs) (when the latter were available) were assessed by two doctors and disputes were settled by a third doctor. ECGs were assessed for heart rhythm, evidence of right atrial abnormality and ventricular hypertrophy. Right atrial abnormality was defined as a P-wave height $\geq 0.25 \mathrm{mV}^{[19]}$ and right ventricular enlargement as an $\mathrm{R}$ wave in $\mathrm{V} 1 \geq 0.7 \mathrm{mV}$ and an $\mathrm{R} / \mathrm{S}$ ratio $\geq 1$ in $\mathrm{V} 1$ with an $\mathrm{R}$ wave $\geq 0.5 \mathrm{mV}$ (dominant $\mathrm{R}$ wave in $\mathrm{V} 1)^{\text {. }}{ }^{[19]}$

\section{Statistical analysis}

Normally distributed continuous variables are reported as means (standard deviations (SDs)) and as medians (interquartile ranges (IQRs)) when skewed. Discrete data are presented as numbers and percentages. Student's $t$-test, the Mann-Whitney $U$-test and the corresponding 95\% confidence Grade 1 disease was minimal involvement

intervals were used to calculate the difference between the two groups, a $p$-value $<0.05$ was set as significant, and Pearson's $\chi^{2}$ test was used to compare categorical variables between the two groups. Statistical analyses were performed using SPSS Statistics for Macintosh version 24.0 (IBM, USA).

\section{Results}

During the study period, 4884 patients were admitted by the Department of Medicine at Dora Nginza Hospital. A total of 745 patients died in hospital, and 905 patients with culturepositive TB were excluded from the study. Among the remaining patients, 242 patients with CLD were identified, of whom 173 (71.5\%) had CLD-TB and 69 (28.5\%) had no history of PTB (Fig. 1). The patients with CLD-TB had a mean (SD) age of 50.8 (15.1) years, and 59.5\% were male; compared with patients with CLD and no history of PTB, they were more likely to be HIV-positive (49.7\% v. $8.7 \%$; $p<0.001$ ) (Table 1 ), had more frequent hospital admissions during the 12 months preceding the current admission, and had longer hospital stays during the index hospitalisation (Table 1).

Fig. 2 shows the frequency of documented symptoms and signs in the 173 patients with CLD-TB. Dyspnoea was the most common presenting symptom, reported in $81.5 \%$, followed by a cough productive

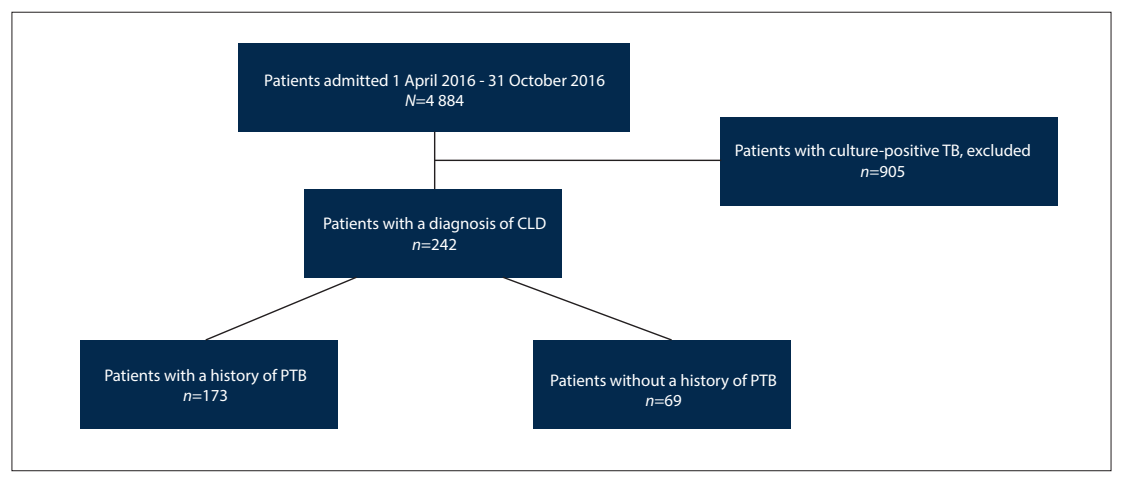

Fig. 1. Study flow chart. $(T B=$ tuberculosis; $C L D=$ chronic lung disease; $P T B=$ pulmonary tuberculosis. $)$

Table 1. Demographic characteristics of patients with chronic lung disease

\begin{tabular}{llll}
\hline & $\begin{array}{l}\text { History of TB } \\
(\mathbf{N = 1 7 3 )}\end{array}$ & $\begin{array}{l}\text { No history of TB } \\
(\boldsymbol{N = 6 9 )}\end{array}$ & $\boldsymbol{p}$-value \\
\hline Age (years), mean (SD) & $50.8(15.1)$ & $54.0(18.2)$ & 0.067 \\
Female, $n$ (\%) & $70(40.5)$ & $37(53.6)$ & 0.063 \\
HIV-positive, $n$ (\%) & $86(49.7)$ & $6(8.7)$ & 0.001 \\
Hypertension, $n$ (\%) & $49(28.3)$ & $26(37.7)$ & 0.157 \\
Diabetes mellitus, $n$ (\%) & $10(5.8)$ & $6(8.7)$ & 0.413 \\
Previous admissions $(n)$, median (IQR) & $2.0(2.0)$ & 0 & 0.001 \\
Duration of current hospitalisation (days), median (IQR) & $5(7)$ & $2(4)$ & 0.002 \\
In-hospital mortality, $n$ (\%) & $30(17.3)$ & $7(10.1)$ & 0.165 \\
Time since completion of TB therapy (months), median (IQR) & $41(101)$ & - & - \\
TB = tuberculosis; SD = standard deviation; IQR = interquartile range. & & &
\end{tabular}


of purulent sputum, reported in $51.4 \%$; haemoptysis was only reported in $18.5 \%$. All 173 CLD-TB patients had chest radiographs available. Fibrosis was present in $48.0 \%$, hyperinflation in $53.2 \%$, pleural reactions in $72.8 \%$, bronchiectasis changes in $83.3 \%$, and a cardiothoracic ratio $>50 \%$ in $33.5 \%$

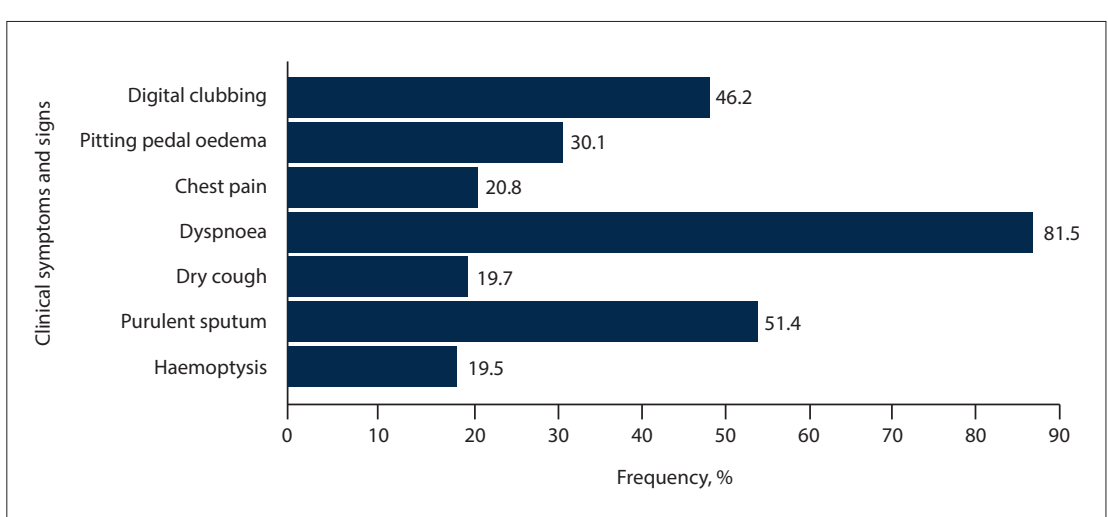

Fig. 2. Documented clinical symptoms and signs at presentation in patients with chronic lung disease and a history of pulmonary tuberculosis $(\mathrm{N}=173)$.

Table 2. Chest radiographic findings in patients with chronic lung disease and a history of pulmonary tuberculosis $(N=173)$

\begin{tabular}{ll}
\hline Variable & $\boldsymbol{n}(\%)$ \\
\hline Fibrosis and traction & $83(48.0)$ \\
Pneumothorax & $7(4.0)$ \\
Bronchiectasis changes & $145(83.8)$ \\
Cavities & \\
$\quad$ Single & $28(16.2)$ \\
$\quad$ Multiple & $31(17.9)$ \\
Destroyed lung & $15(8.7)$ \\
Hyperinflation & $92(53.2)$ \\
Cardiothoracic ratio $>50 \%$ & $58(33.5)$ \\
Pleural reaction & $126(72.8)$ \\
Radiographic grade & \\
$\quad$ Normal chest radiograph & $7(4.0)$ \\
Grade 1 & $16(9.2)$ \\
Grade 2 & $29(16.8)$ \\
Grade 3 & $121(69.9)$ \\
&
\end{tabular}

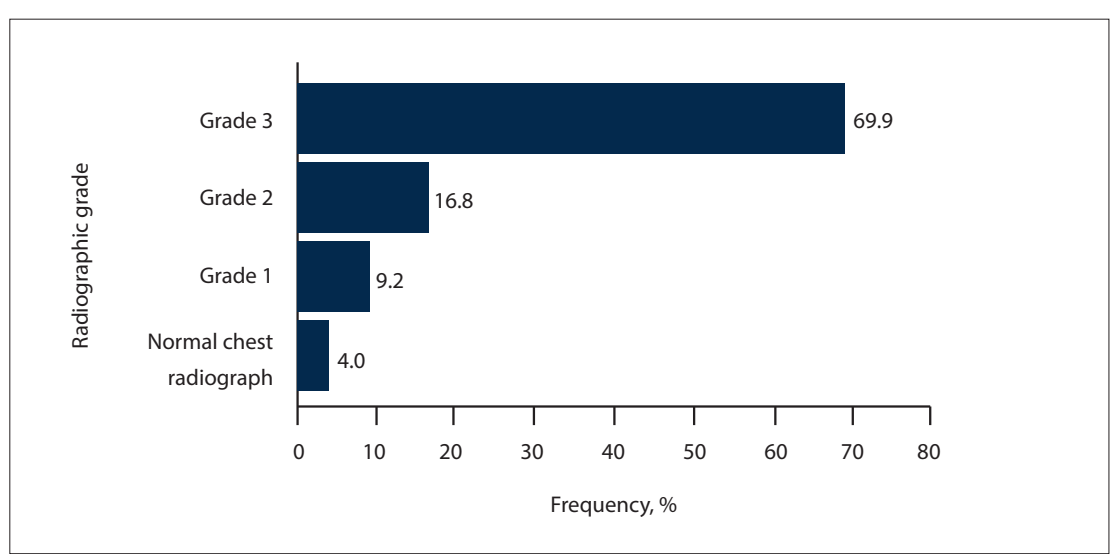

Fig. 3. Chest radiographic grade ${ }^{[18]}$ of patients with chronic lung disease and a history of pulmonary tuberculosis ( $\mathrm{N}=173)$.
(Table 2). Only $4.0 \%$ of CLD-TB patients had normal chest radiographs, and $69.9 \%$ had grade 3 disease according to the classification of Willcox and Ferguson ${ }^{[18]}$ (Fig. 3). All patients had a sputum GeneXpert test, a smear for acid-fast bacilli and tuberculosis culture. Sputum culture for M. tuberculosis was negative in all cases. However, the sputum GeneXpert test and the smear for acid-fast bacilli were positive in $9.0 \%$ and $4.0 \%$ of the CLD-TB cohort, respectively. Haemophilus influenzae was cultured in $29.1 \%$ of the 117 patients whose sputum had $\geq 25$ neutrophils and $\leq 10$ epithelial cells per low-power field on Gram stain and was sent for routine microscopy and culture (Fig. 4).

Twelve-lead ECGs were available for 73 patients with CLD-TB. Multifocal atrial tachycardia was the most prevalent rhythm (78.1\%), followed by sinus rhythm in only $13.7 \%$. Atrial fibrillation and atrial flutter were present in $6.8 \%$ and $1.4 \%$, respectively. Right atrial abnormality, defined above, ${ }^{[19]}$ was present in $49.7 \%$, and $\mathrm{P}$-wave right axis deviation was present in $74.0 \%$. Additionally, right ventricular enlargement, defined as an $\mathrm{R}$ wave in $\mathrm{V} 1>0.7 \mathrm{mV}$ and an $\mathrm{R} / \mathrm{S}$ ratio $>1$ with $\mathrm{R}>0.5 \mathrm{mV},{ }^{[19]}$ was present in $21.9 \%$ and $24.7 \%$, respectively. We could not identify predictors of in-hospital mortality in our study (Fig. 5).

\section{Discussion}

The key findings of our study were as follows: (i) a large proportion of patients with CLD in our cohort had had previous PTB; (ii) CLD-TB patients were predominantly male; (iii) CLD-TB patients were more likely than CLD patients without a history of PTB to be HIV-positive; (iv) CLD-TB patients had longer hospital stays than CLD patients without a history of PTB; $(v)$ in CLD-TB patients in whom routine sputum microscopy and culture was done, $H$. influenzae was the most frequently cultured micro-organism; and $(v i)$ multifocal atrial tachycardia was the predominant rhythm in CLD-TB patients who had an ECG, and a substantial proportion of patients had ECG evidence of right atrial hypertrophy and right ventricular hypertrophy.

This article is the first to report sputum micro-organisms in a patient population with CLD-TB. The patients had numerous sputum micro-organisms cultured. H. influenzae was the most frequently isolated sputum microorganism (29.1\%), followed by Pseudomonas aeruginosa and Klebsiella pnuemoniae (9.4\% and $7.7 \%$, respectively). Only $13.7 \%$ of the patients with CLD-TB who had routine sputum culture had culture-negative sputum. The presence of sputum micro-organisms, particularly $P$. aeruginosa, in patients with non-cystic fibrosis bronchiectasis predicts a poor clinical outcome characterised by a progressive decline in lung function and recurrent severe exacerbations of respiratory symptoms. ${ }^{[20]}$ In addition, there is evidence 


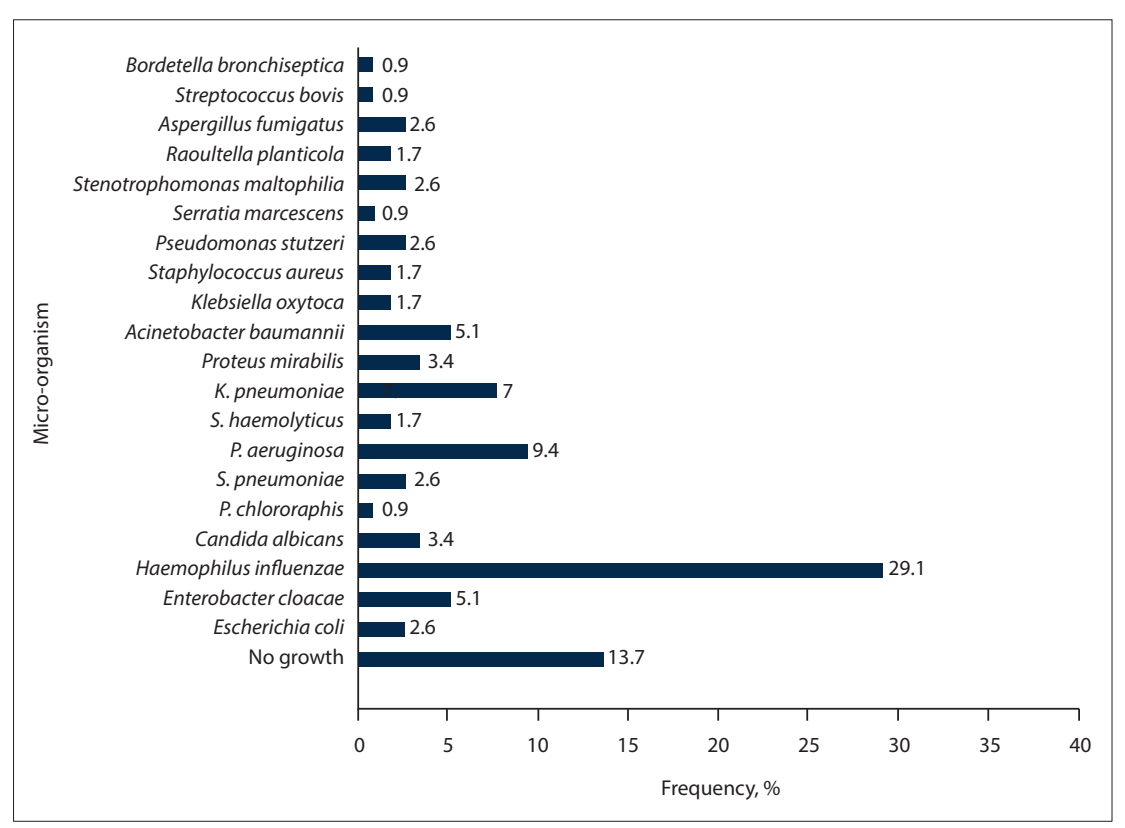

Fig. 4. Micro-organisms cultured on routine microscopy and culture in patients with chronic lung disease with a history of pulmonary tuberculosis whose sputum had $\geq 25$ neutrophils and $\leq 10$ epithelial cells per low-power field on Gram stain ( $\mathrm{N}=117)$.

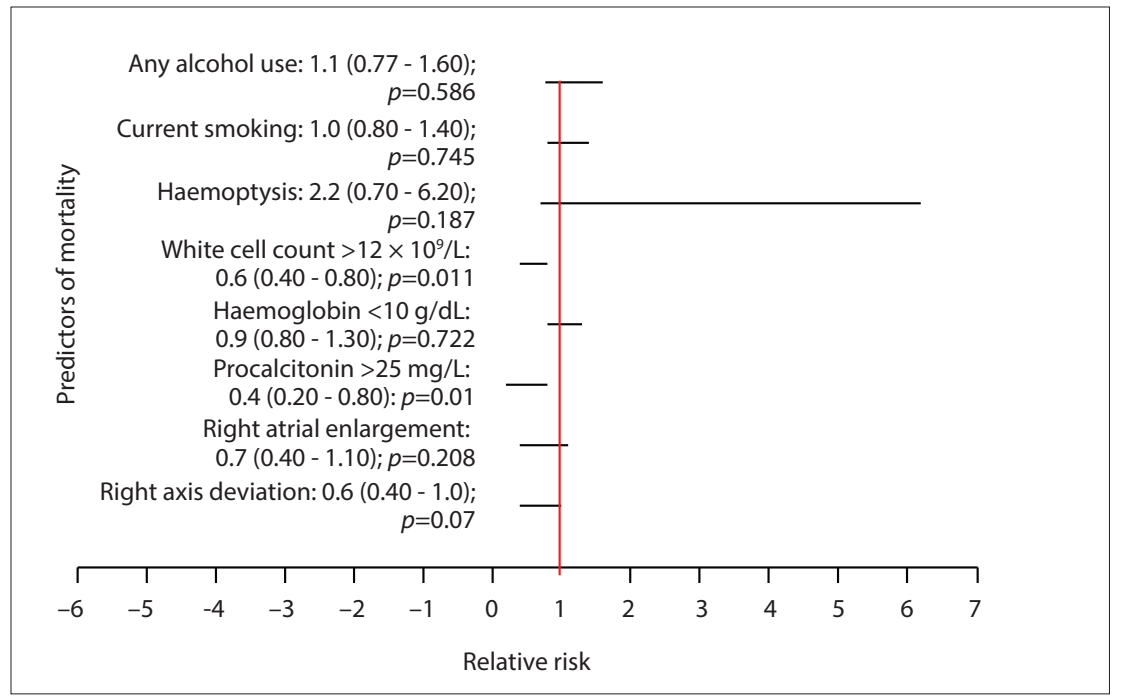

Fig. 5. Relative risk (confidence intervals) of in-hospital death in patients with chronic lung disease with a history of pulmonary tuberculosis.

that eradication of such micro-organisms leads to fewer exacerbations and therefore fewer hospitalisations. ${ }^{[21,22]}$ Such treatment presents a viable management strategy for patients with CLD-TB in resourceconstrained settings to curb the costs of recurrent admissions and long hospital stays.

Historically, ECG changes have been reported in the setting of chronic obstructive pulmonary disease (COPD). To our knowledge, this is the first study to report ECG changes in patients with CLDTB. A P wave $\geq 0.25 \mathrm{mV}$ in leads I, II and AVF, a P-wave axis $\geq 80^{\circ}$ and a QRS axis $\geq 90^{\circ}$ have traditionally been regarded of lung disease as defined by the Willcox and Ferguson $^{[18]}$ grading system.

Disability and ill health from tuberculosis persist beyond the period of active disease. In a population of 3993 patients with fully treated TB, Hoger et al. ${ }^{[27]}$ reported an average of 3.6 more years of potential life lost than in a similar population without a history of TB. Furthermore, Miller et al. ${ }^{[28]}$ estimated that chronic morbidity accounted for $78 \%$ of quality-adjusted life-years (QALYs) lost in patients with cured TB; acute illness and mortality were responsible for only $4 \%$ and $18 \%$ of QALYs lost, respectively. Although we found no statistically significant difference in hospital mortality in patients with CLT-TB compared with those with CLD and no previous PTB (17.3\% v. 10.1\%; $p=0.165)$, patients with CLD-TB had more frequent and longer hospital admissions, highlighting the impact of previous $\mathrm{TB}$ on quality of life and on public health. The presence of residual respiratory symptoms after completion of PTB therapy has been widely reported, with a prevalence of up to 97\%. ${ }^{[8,11-13]}$ Musafiri et al. ${ }^{[13]}$ reported that these symptoms can persist up to a year after the completion of TB therapy, Our patients were admitted with respiratory symptoms after a median of 41 months (IQR 101) after completion of TB therapy.

Complete resolution of chest radiographic abnormalities after completion of PTB therapy is reported in only $59.6 \%$ of fully treated patients. ${ }^{[14]}$ Residual parenchymal changes account for the majority of residual chest radiographic abnormalities after completion of PTB therapy, while pleural and mediastinal abnormalities account for $23.6 \%$ and $9.0 \%$, respectively. ${ }^{[14]}$ Cardiotopographic imaging identifies 5\% more residual pleural abnormalities than plain chest radiography. ${ }^{[29]}$ Of our patient cohort, $96.0 \%$ had abnormal chest radiographs.

The respiratory physiological manifestations of post-TB lung disease are varied. ${ }^{[18,30]}$ In a cross-sectional study by Mbatchou Ngahane et al. ${ }^{[30]}$ of 269 patients successfully treated for PTB, only $54.6 \%$ of the cohort had normal lung function tests. The remainder of the patients had restrictive (31.6\%) or obstructive changes (4.1\%) or a mixed pattern (5.2\%). Willcox and Ferguson $^{[18]}$ reported obstructive changes in $68 \%$ of their patients and restrictive changes in $17 \%$, while $15 \%$ had normal lung function tests. Lung function testing revealing obstructive changes and bronchodilator response therefore offers a viable therapeutic strategy that needs to be studied further in this patient population. We do not have lung 
function results for our cohort, partly owing to unavailability of this form of testing in our hospital. Finally, long-term oxygen therapy has been shown to improve survival, reduce hospital readmission rates and improve quality of life in hypoxic stable chronic obstructive airway disease $(\mathrm{COAD})^{[31,32]}$ and is recommended in our local guidelines for the management of hypoxic COAD ${ }^{[33]}$ However, it is still to be investigated in post-TB lung disease with hypoxia.

\section{Study limitations}

The limitations of this study are its retrospective and single-centre nature, the lack of long-term follow-up and lack of lung function testing, absence of data on hospital visits outside our unit, and the facts that few patients had ECGs and we did not report on the prevalence of hypoxia as measured by arterial blood gases. Additionally, we do not have information on patients who may have been treated empirically for TB on the basis of their abnormal chest radiographs while awaiting sputum results.

\section{Conclusions}

The objective of this study was to describe the clinical profile and in-hospital outcomes of patients with CLD-TB compared with patients with CLD and no history of PTB in a resource-constrained setting. We found that patients with CLD-TB had persistent respiratory symptoms, residual abnormal findings on chest radiographs, and ECG evidence of right atrial and right ventricular enlargement. In addition, they were more likely to have recurrent hospital admissions than patients with CLD without previous pulmonary TB. Although there was a trend towards increased in-hospital mortality, this was not statistically significant.

\section{Declaration. None.}

Acknowledgements. The authors thank Mrs Thembisa Gabayi for finding the patient records, Mrs Zikhona Mkoko for creating the figures, and the Dora Nginza internal medicine staff for caring for the patients.

Author contributions. PM designed the study and collected the data, SN, LCM and FN collected the data, and RM and SD supervised this work.

Funding. None.

Conflicts of interest. None.

1. World Health Organization. Global Tuberculosis Report 2016. 2016. http://www.who.int/tb/ publications/global_report/gtbr2016_executive_summary.pdf (accessed 1 April 2017).

2. Lawn SD, Churchyard G. Epidemiology of HIV-associated tuberculosis. Curr Opin HIV AIDS 2009;4(4):325-333. https://doi.org/10.1097/COH.0b013e32832c7d61

3. Lawn SD, Mwaba P, Bates M, et al. Advances in tuberculosis diagnostics: The Xpert MTB/RIF assay and future prospects for a point-of-care test. Lancet Infect Dis 2013;13(4):349-361. https://doi.org/10.1016/ S1473-3099(13)70008-2

4. Lawn SD, Zumla AI. Tuberculosis. Lancet 2011;378(9785):57-72. https://doi.org/10.1016/S01406736(10)62173-3

5. World Health Organization. Global Tuberculosis Report 2015. 2015. http://apps.who.int/iris/ bitstream/10665/191102/1/9789241565059_eng.pdf (accessed 25 January 2019).

6. Nahid P, Dorman SE, Alipanah N, et al. Official American Thoracic Society/Centers for Disease Control and Prevention/Infectious Diseases Society of America Clinical Practice Guidelines: Treatment of drug-susceptible tuberculosis. Clin Infect Dis 2016;63(7):e147-e195. https://doi. org/10.1093/cid/ciw376
7. Chakaya J, Kirenga B, Getahun H. Long term complications after completion of pulmonary tuberculosis treatment: A quest for a public health approach. J Clin Tuberc Other Mycobact Dis 2016;3(May):10-12. https://doi.org/10.1016/j.jctube.2016.03.001

8. Singla N, Singla R, Fernandes S, Behera D. Post treatment sequelae of multi-drug resistant tuberculosis patients. Indian J Tuberc 2009;56(4):206-212. http://medind.nic.in/ibr/t09/i4/ibrt09i4p206.pdf (accessed 5 February 2019).

9. Muniyandi M, Rajeswari R, Balasubramanian R, et al. Evaluation of post-treatment health-related quality of life (HRQoL) among tuberculosis patients. Int J Tuberc Lung Dis 2007;11(8):887-892.

10. Rajeswari R, Muniyandi M, Balasubramanian R, Narayanan PR. Perceptions of tuberculosis patients about their physical, mental and social well-being: A field report from south India. Soc Sci Med 2005;60(8):1845-1853. https://doi.org/10.1016/j.socscimed.2004.08.024

11. Nihues SdeS, Mancuzo EV, Sulmonetti N, et al. Chronic symptoms and pulmonary dysfunction in post-tuberculosis Brazilian patients. Braz J Infect Dis 2015;19(5):492-497. https://doi.org/10.1016/j. bjid.2015.06.005

12. Ramos LMM, Sulmonett N, Ferreira CS, Henriques JF, de Miranda SS. Functional profile of patients with tuberculosis sequelae in a university hospital. J Bras Pneumol 2006;32(1):43-47. https://doi. org/10.1590/\$1806-37132006000100010

13. Musafiri S, Dusabejambo V, Munganyinka BC, Manzi O, Kalisa L, Rutayisire PC. The aftermath of pulmonary tuberculosis: Predictors of severe pulmonary sequelae and quality of life of patients visiting a tertiary level of care in Rwanda, East Africa. Austin J Pulm Respir Med 2015;2(2):1027. http:// austinpublishinggroup.com/pulmonary-respiratory-medicine/fulltext/ajprm-v2-id1027.php\#Title (accessed 4 February 2019).

14. Menon B, Nima G, Dogra V, Jha S. Evaluation of the radiological sequelae after treatment completion in new cases of pulmonary, pleural, and mediastinal tuberculosis. Lung India 2015;32(3):241-245. https://doi.org/10.4103/0970-2113.156233

15. Al-Hajjaj MS, Joharjy IA. Predictors of radiological sequelae of pulmonary tuberculosis. Acta Radiol 2000;41(6):533-537. https://doi.org/10.1080/028418500127346153

16. Statistics South Africa. Nelson Mandela Bay. http://www.statssa.gov.za/?page_id=1021\&id=nelsonmandela-bay-municipality (accessed 26 April 2017).

17. Mandell LA, Wunderink RG. Pneumonia. In: Kasper D, Fauci A, Hauser S, Longo D, Jameson JL, Loscalzo I eds. Harrison's Principles of Internal Medicine. 19th ed. New York: McGraw-Hill, 2015:803-813.

18. Willcox PA, Ferguson AD. Chronic obstructive airways disease following treated pulmonary tuberculosis. Respir Med 1989;83(3):195-198. https://doi.org/10.1016/S0954-6111(89)80031-9

19. Mann DL, Zipes DP, Libby P, Bonow RO. Braunwald's Heart Disease: A Textbook of Cardiovascular Medicine. 10th ed. Philadelphia: Elsevier/Saunders, 2015.

20. Martínez-García MA, Soler-Cataluña J-J, Perpiñá-Tordera M, Román-Sánchez P, Soriano J. Factors associated with lung function decline in adult patients with stable non-cystic fibrosis bronchiectasis. Chest 2007;132(5):1565-1572. https://doi.org/10.1378/chest.07-0490

21. White L, Mirrani G, Grover M, Rollason J, Malin A, Suntharalingam J. Outcomes of Pseudomona eradication therapy in patients with non-cystic fibrosis bronchiectasis. Respir Med 2012;106(3):356360. https://doi.org/10.1016/j.rmed.2011.11.018

22. Haworth CS, Foweraker JE, Wilkinson P, Kenyon RF, Bilton D. Inhaled colistin in patients with bronchiectasis and chronic Pseudomonas aeruginosa infection. Am J Respir Crit Care Med 2014;189(8):975-982. https://doi.org/10.1164/rccm.201312-22080C

23. Surawicz B, Knilans T. Chou's Electrocardiography in Clinical Practice. 6th ed. Philadelphia: WB Saunders, 2008:273-326.

24. Spodick DH, Hauger-Klevene JH, Tyler JM, Muench H, Dorr CA. The electrocardiogram in pulmonary emphysema. Am Rev Respir Dis 1963;88(1):14-19. https://www.atsjournals.org/doi/ abs/10.1164/arrd.1963.88.1.14 (accessed 4 February 2019).

25. Calatayud JB, Abad JM, Khoi NB, Stanbro WW, Silver HM. P-wave changes in chronic obstructive pulmonary disease. Am Heart J 1970;79(4):444-453. https://doi.org/10.1016/0002-8703(70)90248-6

26. Hurst JW, Baliepally R, Spodick DH. Electrocardiographic screening for emphysema: The frontal plane p axis. Clin Cardiol 1999;22(3):226-228. https://doi.org/10.1002/clc.4960220313

27. Hoger S, Lykens K, Beavers SF, Katz D, Miller TL. Longevity loss among cured tuberculosis patient and the potential value of prevention. Int J Tuberc Lung Dis 2014;18(11):1347-1352. https://doi. org $/ 10.5588 /$ ijtld. 14.0242

28. Miller TL, McNabb SJN, Hilsenrath P, Pasipanodya J, Weis SE. Personal and societal health quality lost to tuberculosis. PloS One 2009;4(4):e5080. https://doi.org/10.1371/journal.pone.0005080

29. Kwon JS, Cha SI, Jeon KN, et al. Factors influencing residual pleural opacity in tuberculous pleura effusion. J Korean Med Sci 2008;23(4):616-620. https://doi.org/10.3346/jkms.2008.23.4.616

30. Mbatchou Ngahane BH, Nouyep J, Nganda Motto M, et al. Post-tuberculous lung function impairment in a tuberculosis reference clinic in Cameroon. Respir Med 2016;114(May):67-71. https://doi. org/10.1016/j.rmed.2016.03.007

31. Nocturnal Oxygen Therapy Trial Group. Continuous or nocturnal oxygen therapy in hypoxemic chronic obstructive lung disease: A clinical trial. Ann Intern Med 1980;93(3):391-398. https://doi org $/ 10.7326 / 0003-4819-93-3-391$

32. Long term domiciliary oxygen therapy in chronic hypoxic cor pulmonale complicating chronic bronchitis and emphysema. Report of the Medical Research Council Working Party. Lancet 1981;317(8222):681-686. https://doi.org/10.1016/S0140-6736(81)91970-X

33. Abdool-Gaffar MS, Ambaram A, Ainslie GM, et al. Guideline for the management of chronic obstructive pulmonary disease - 2011 update. S Afr Med J 2011;101(1):63-73

Accepted 21 August 2018 